\title{
Perinatal outcome in pregnancies complicated with oligohydramnios at term
}

\author{
Kambham Bhaskar Suneetha, Silpa Parvathanenidey*
}

Department of Gynaecology and Obstetrics, SVS Medical College, Mahabubnagar, Telangana, India

Received: 10 January 2022

Revised: 24 January 2022

Accepted: 25 January 2022

\section{*Correspondence:}

Dr. Silpa Parvathanenidey,

E-mail: drsilpaparvathaneni66@gmail.com

Copyright: $\odot$ the author(s), publisher and licensee Medip Academy. This is an open-access article distributed under the terms of the Creative Commons Attribution Non-Commercial License, which permits unrestricted non-commercial use, distribution, and reproduction in any medium, provided the original work is properly cited.

\section{ABSTRACT}

Background: AFI of less than or equal to five $\mathrm{cm}$ is considered oligohydramnios. Various approaches, such as NST, acoustic stimulation, and foetal Doppler velocimetry, are useful in assessing foetal well-being and identifying pregnancies at risk of postnatal complications. The goal of this study was to learn about the negative perinatal outcomes in pregnant women who had oligohydramnios at term and to assess the efficacy of AFI in predicting foetal distress and caesarean delivery.

Methods: A retrospective and comparative study of singleton pregnancies outcomes in 60 women diagnosed with oligohydramnios by USG after 37 weeks of pregnancy, compared to 60 women who did not have oligohydramnios and were matched for other factors. Some criteria for inclusion and exclusion were utilised. The data was analysed using statistical criteria such as mean, standard deviation, and chi square test sensitivity, specificity, PPV, and NPV.

Results: The occurrence of non-reactive and re-active NST patterns differed significantly between the two groups. In comparison to women with AFI $>5 \mathrm{~cm}$, women with AFI $5 \mathrm{~cm}$ have a higher rate of labour induction. LBW $(2.5 \mathrm{~kg})$ was more common in women with oligohydramnios, and LSCS rates were higher in oligohydramnios-complicated pregnancies.

Conclusions: After 37 weeks of pregnancy, an AFI of less than $5 \mathrm{~cm}$ is a sign of poor perinatal outcome. AFI can be used in conjunction with other foetal monitoring techniques. AFI is a useful screening test for predicting foetal distress during labour that necessitates a caesarean section.

Keywords: Non stress test, Contraction stress test, Fetal acoustic stimulation test, Biophysical profile, Vibroacoustic stimulation, Doppler velocimetry, Fetal heart rate tracing, Foetal stimulation test

\section{INTRODUCTION}

The foetus benefits from the amniotic fluid that surrounds the developing foetus in the amniotic sac. The regulation of amniotic fluid volume and content, despite decades of research, is still a mystery. This is due in part to the complexity of amniotic fluid dynamics, which involve an intriguing interaction of numerous amniotic fluid secretion and excretion sites. Because the aetiology, therapy, and outcome of late-onset oligohydramnios differ from those of early-onset oligohydramnios, a sample of women with oligohydramnios at term pregnancies was chosen. ${ }^{1,2}$ The importance of amniotic fluid volume as a foetal status indicator and oligohydramnios as an indicator of chronic foetal hypoxia has only recently been recognised. The amniotic fluid content may now be measured quite precisely because of advancements in ultrasonographic techniques. Although there are subjective and semiquantitative ways for determining amniotic fluid content using ultrasonography, the optimum technique is still debated. The four quadrant approach of calculating amniotic fluid index (AFI) described by Phelan et al in 
1987, however, is widely recognised by the authors. Interobserver and interobserver variance, transducer pressure, maternal hydration, foetal movements, transducer type, foetal presentation, and gestational age have all been studied in relation to their impact on the amniotic fluid index. ${ }^{3}$ For antepartum and intrapartum foetal surveillance, various approaches have been described, including Non stress test (NST), Contraction stress test (CST), Fetal acoustic stimulation test (FAST), Biophysical profile (BPP), Vibroacoustic stimulation (VAST), doppler velocimetry, Fetal heart rate (FHR) tracing, foetal stimulation test, and foetal scalp blood $\mathrm{pH}$ estimate. Each strategy has its own set of advantages and disadvantages. Phelan et al first described oligohydramnios as having an amniotic fluid index of less than $5 \mathrm{~cm}$. Numerous studies have linked oligohydramnios to a slew of negative pregnancy outcomes, including foetal discomfort, low birth weight, perinatal morbidity, perinatal mortality, and a higher rate of caesarean delivery. ${ }^{3,4,5}$ However, several studies demonstrate that the amniotic fluid index is a poor predictor of negative outcomes, and the existence of a condition such as isolated term oligohydramnios has been questioned by certain writers. Thus, the purpose of this study is to determine the relevance of oligohydramnios in predicting perinatal outcome and caesarean section rates in pregnancies that go longer than 37 weeks. The goals are to investigate and analyse the perinatal outcome in oligohydramnios (AFI 5) at term, as well as the utility of AFI in predicting foetal distress and caesarean delivery.

\section{METHODS}

A retrospective and comparative study of singleton pregnancies done in SVS Medical College in department of Obstetrics and gynaecology for a period of one year from May 2020 to April 2021. This study compared 60 patients with oligohydramnios diagnosed by ultrasound after 37 weeks of pregnancy to 60 controls with no oligohydramnios and matched for other characteristics such as age, parity, gestational age, and any pregnancy complications. A full history was gathered and a thorough examination was performed on all of the cases that were chosen. There was a search for clinical evidence of oligohydramnios. Previous obstetric records and ultrasound reports were scrutinised again. Ultrasound examinations were performed on all of the women, and the amniotic fluid index was computed using the fourquadrant amniotic fluid volume measuring technique. Blood tests were performed on all women as part of their baseline examinations, which included $\mathrm{Hb}$ percent, blood group, and Rh typing. NST was performed on all patients, while BPP was performed on a select subset. This study included 37 weeks of pregnancy, an amniotic fluid index of less than $5 \mathrm{~cm}$, intact membranes, and a singleton pregnancy with cephalic presentation. This study excluded congenital abnormalities, ruptured membranes, malpresentation, and multiple gestation at a gestational age of less than 37 weeks. In both the study and control groups, the management protocol was similar. High-risk women were induced with dinoprostone gel (PGE2) or oxytocin if they had preeclampsia, post-term pregnancy, or nonreactive NST. Women who had no other risk factors were permitted to go into labour on their own, and daily NST and weekly BPP were performed. During labour, all of them were monitored by continuous electronic foetal monitoring. Amniotic fluid was characterised as clear, thin meconium stained liquor, or thick meconium stained liquor during artificial rupture of membranes, which was performed on all women. LSCS or forceps delivery was used for those who developed significant variable decelerations and repetitive late decelerations or other ominous FHR patterns with or without meconium stained liquor that persisted despite corrective measures such as changing the maternal position, hydration, 02 inhalation, and stopping oxytocin. All newborns were seen by neonatologists, and endotracheal intubation was performed when the amniotic fluid was thickly stained with meconium.

\section{RESULTS}

This was a prospective case control study of 60 pregnant women who were more than 37 weeks pregnant and had an AFI of less than $5 \mathrm{~cm}$ compared to those who had an AFI of 5 to $20 \mathrm{~cm}$. In both groups, other characteristics such as age, parity, and gestational age were matched.

Table 1: Demographics.

\begin{tabular}{|lll|}
\hline Variables & Study Group & Control Group \\
\hline Mean Age & 24.6 & 23.7 \\
\hline Gravidity & 1.5 & 1.8 \\
\hline $\begin{array}{l}\text { Mean } \\
\text { gestational age }\end{array}$ & 40.3 & 40.8 \\
\hline Mean AFI & 4.38 & 9.64 \\
\hline
\end{tabular}

Table 2: Perinatal outcome.

\begin{tabular}{|ll|l|}
\hline $\begin{array}{l}\text { Outcome } \\
\text { parameters }\end{array}$ & $\begin{array}{l}\text { Study Group } \\
(\mathbf{n = 6 0})\end{array}$ & $\begin{array}{l}\text { Control Group } \\
(\mathbf{n}=60) \%\end{array}$ \\
\hline Non-reactive NST & $22(36.6 \%)$ & $13(21.6 \%)$ \\
\hline FHR & $40(66.6 \%)$ & $24(40 \%)$ \\
\hline $\begin{array}{l}\text { Thick Meconium- } \\
\text { stained liquor }\end{array}$ & $26(43.3 \%)$ & $10(16.6 \%)$ \\
\hline Labour induction & $30(50 \%)$ & $16(26.6 \%)$ \\
\hline
\end{tabular}

Table 3: Perinatal outcome of fetal distress.

\begin{tabular}{|ll|l|}
\hline $\begin{array}{l}\text { Outcome } \\
\text { parameters }\end{array}$ & $\begin{array}{l}\text { Study Group } \\
(\mathbf{n = 6 0}) \%\end{array}$ & $\begin{array}{l}\text { Control Group } \\
(\mathbf{n}=60) \%\end{array}$ \\
\hline $\begin{array}{l}\text { LSCS for fetal } \\
\text { distress }\end{array}$ & $28(46.6 \%)$ & $14(23.3 \%)$ \\
\hline $\begin{array}{l}\text { Forceps delivery } \\
\text { for fetal distress }\end{array}$ & $5(8.3 \%)$ & $2(3.3 \%)$ \\
\hline
\end{tabular}

Table 1 shows that the average age of the study groups and control groups was 24.6 and 23.7 years, respectively. The majority of them were primi-gravidas, with a mean 
gravidity of of 1.5 in the study group and 1.8 in the control group. Only individuals with good rates were chosen for the study, and all were 37 weeks pregnant, with a mean gestational age of 40.3 weeks for the study group and 40.8 weeks for the control group. Preeclampsia and post-term pregnancy were common prenatal problems for more than half of the women. The amniotic fluid index (AFI) was evaluated using a four-quadrant semi-quantitative ultrasonography technique, and those with an AFI of less than $5 \mathrm{~cm}$ were classified as oligohydramnios, while those with an AFI of $5 \mathrm{~cm}$ to $20 \mathrm{~cm}$ were classified as normal. The average AFI in the oligohydramnios group was 4.38 $\mathrm{cm}$, while the control group's average AFI was $9.64 \mathrm{~cm}$.

Table 4: Perinatal outcome of APGAR score <7.

\begin{tabular}{|lll|}
\hline $\begin{array}{l}\text { APGAR score } \\
<7\end{array}$ & $\begin{array}{l}\text { Study Group } \\
(\mathbf{n}=\mathbf{6 0}) \%\end{array}$ & $\begin{array}{l}\text { Control Group } \\
(\mathbf{n = 6 0}) \%\end{array}$ \\
\hline $\mathbf{1} \mathbf{~} \mathbf{m i n}$ & $22(36.6 \%)$ & $11(18.3 \%)$ \\
\hline $\mathbf{5} \mathbf{~ m i n}$ & $10(16.6 \%)$ & $5(8.3 \%)$ \\
\hline
\end{tabular}

Table 5: Perinatal outcome based on birth weight.

\begin{tabular}{|lll|}
\hline $\begin{array}{l}\text { Birth weight } \\
\leq 2.5 \mathrm{Kg}\end{array}$ & $\begin{array}{l}\text { Study group } \\
(\mathrm{n}=60), \%\end{array}$ & $\begin{array}{l}\text { Control group } \\
(\mathrm{n}=60), \%\end{array}$ \\
\hline
\end{tabular}

Table 6: Perinatal outcome based on neonatal ward admission and deaths.

\begin{tabular}{|lll|}
\hline Outcomes & $\begin{array}{l}\text { Study Group } \\
(\mathbf{n}=60), \%\end{array}$ & $\begin{array}{l}\text { Control Group } \\
(\mathbf{n}=60), \%\end{array}$ \\
\hline $\begin{array}{l}\text { Neonatal ward } \\
\text { admission }\end{array}$ & $28(46.6 \%)$ & $8(13.3 \%)$ \\
\hline Neonatal death & $6(10 \%)$ & $3(5 \%)$ \\
\hline
\end{tabular}

Table 2 shows that non-reactive NST was found more frequently in the oligohydramnios group (36.6 percent) than in the control group ( 21.6 percent $)(p=0.05)$. Variable decelerations were the most common form of FHR decelerations in CTG, which were recorded more frequently in the oligohydramnios group (66.6 percent). The study yielded a $\mathrm{p}=0.69$, which is statistically insignificant. In the oligohydramnios group (43.3 percent), thick meconium stained amniotic fluid was more than twice as common as in the control group (16.6 percent). Induction of labour was significantly more common (50 percent) in the oligohydramnios group than in the control group. $\mathrm{P}<0.001$ indicated that the difference was statistically significant.

Table 3 shows that fifty percent of women with AFI $<5$ $\mathrm{cm}$ developed fetal distress. $46.6 \%$ of patients were delivered by caesarean section and $8.3 \%$ by forceps. The difference in occurrence of fetal distress and caesarean section for fetal distress in study group and control group was statistically non-significant $(\mathrm{p}=0.99)$. AFI can be used as a screening test to predict foetal distress and the need for LSCS. The sensitivity was $75 \%$, the specificity was
$60 \%$, the positive predictive value was $48 \%$, and the negative predictive value was 88 percent. If oligohydramnios was accompanied with non-reactive NST, the likelihood of a caesarean delivery was high.

Table 4 shows that In the oligohydramnios group, the mean Apgar score was higher than in the control group. The oligohydramnios group had the lowest 5-minute Apgar score compared to the normal volume group, however the difference was not statistically significant $(\mathrm{p}=0.93)$.

Table 5 shows that for the oligohydramnios group and those with normal AFI, the mean birth weight was $2.58 \mathrm{~kg}$ and $2.86 \mathrm{~kg}$, respectively. 60 percent of women with an AFI of less than $5 \mathrm{~cm}$ and 30 percent of women with an AFI of more than $5 \mathrm{~cm}$ had a birth weight of less than 2.5 $\mathrm{kg}$.

Table 6 shows that a total of 46.6 percent of babies born to women with an AFI of less than $5 \mathrm{~cm}$ were admitted to a neonatal hospital due to various newborn problems. Only $13.3 \%$ of the control group was admitted to a newborn unit. There was a statistically significant difference between the two groups $(p<0.01)$. Two of the infants in the study group had bilateral CTEV. In the oligohydramnios group, there were six early infant fatalities, while in the control group, there were three. Various adverse perinatal outcome characteristics were equally common in the control group, however they were much lower than in the study group.

\section{DISCUSSION}

The varied outcomes are comparable to those of similar research conducted in India and abroad. After 40 weeks of pregnancy, the volume of amniotic fluid is known to decrease. In the current study, 12 percent of women with an AFI of less than $5 \mathrm{~cm}$ had a post-term pregnancy, compared to 10 percent, 15.38 percent, and 25 percent in studies by Abhijeet et al, Chandra et al, and Sriya et al, respectively. Oligohydramnios is caused by hypertensive diseases that induce prolonged placental insufficiency. ${ }^{6,7,8}$ In the study by Abhijeet et al, Chandra et al, and Sriya et al studies, 35 percent, 32.5 percent, 38.46 percent, and 31 percent of the oligohydramnios respectively. ${ }^{6,7,8}$ In mature pregnancies, any cause of chronic placental insufficiency, such as chronic abruptio and diabetes mellitus, can result in foetal growth limitation and oligohydramnios. Women with an AFI of less than $5 \mathrm{~cm}$ had a high rate of nonreactive non-stress tests. In this study, the rate of nonreactive NST was 36.6 percent, which is comparable to Abhijeet et al study. ${ }^{6}$ In pregnant women with an AFI of less than $5 \mathrm{~cm}$, FHR decelerations suggestive of foetal distress are common during the intrapartum period. Variable decelerations due to cord compression are the most common. The FHR pattern observed in 66.6 percent of the participants in this study is similar to 60 percent, 48 percent, and 36.11 percent in investigations by Abhijeet et al, Casey et al, and Sriya et al. ${ }^{6-8}$ Meconium-stained 
amniotic fluid is high in women with an AFI of less than 5 $\mathrm{cm}$. In the current study, 43.3 percent of the study group had thick meconium stained liquor, which is similar to Abhijeet et al study (48 percent). These findings contradict those of Baron et al, and this could be attributable to a lower proportion of women who had reached 40 weeks. $^{9}$ Grubb et al found that 99 percent of women with an AFI of less than $5 \mathrm{~cm}$ and sustained deceleration had meconium stained fluid in a study. ${ }^{10}$ LSCS rates for foetal distress in pregnant women with an amniotic fluid index of less than $5 \mathrm{~cm}$ vary according to research. When compared to prior studies, the current study found that 46.6 percent of women underwent LSCS for foetal distress. Oligohydramniosis (AFI $5 \mathrm{~cm}$ ) has been utilised as a screening test for the onset of foetal distress during intrapartum period. The sensitivity, specificity, positive predictive value, and negative predictive value reported in various investigations are nearly identical. The sensitivity of oligohydramnios (AFI $5 \mathrm{~cm}$ ) in predicting foetal distress and the need for LSCS was $75 \%$, while the negative predictive value was 88.0 percent. However, the specificity and positive predictive value were poor. As a result, this can be used as a screening test for foetal distress during the intrapartum phase, which may necessitate a caesarean birth. Those with oligohydramnios and nonreactive NST had a higher rate of LSCS. Even with reactive NST, 36.6 percent of pregnant women experience foetal distress, and LSCS was performed, which was equivalent to Kumar et al study. ${ }^{11}$ Women with nonreactive NST had a 21.6 percent caesarean rate in the control group, while women with reactive NST had only a 13 percent caesarean rate. The study group's mean 1 minute and 5 minute Apgar scores were 7 and 8.6, respectively, while the control groups were 8.1 and 9.9. The 5-minute Apgar score of 7 is seen in $16.6 \%$ of the oligohydramnios group and is comparable to other research studies..$^{7-9,11-13}$ In the oligohydramnios group, the average birth weight is lower. Low birth weight occurs in 60 percent of babies, which is similar to other Indian research (Chandra et al 61.53 percent and Sriya et al 58.38 percent). ${ }^{7,8}$ The high rate of low birth weight could be due to persistent placental insufficiency, which limits foetal growth. For various morbidities such as neonatal seizures, birth hypoxia, and meconium aspiration, 46.6 percent of neonates were hospitalised to a neonatal ward. This contradicts the findings of Morris et al and Casey et al. ${ }^{9,13}$ Both authors, however, relate to admission to neonatal intensive care units (NICUs). In a study by Sriya et al, admission to a neonatal ward was found to be even more common (88.88 percent). One neonate has bilateral congenital talipes equino varus. Though oligohydramnios can cause CTEV due to compression, a large number of instances is required to determine the importance of the link. There were six neonatal fatalities among the study cases, but only three neonatal death among the controls. One case of infant death was reported in the Chandra et al investigation. ${ }^{7}$ There was no fatality in the studies by Baron et al and Casey et al, owing to good newborn intensive care unit facilities. ${ }^{9}$ Early newborn deaths were the cause of all six deaths in the current study group, and they were all unbooked cases. Four of them were born with severe hypoxia and were unable to be revived. Two of the patients had meconium aspiration syndrome. Two neonates died of meconium aspiration in the control group as well.

\section{Limitations}

Our study was conducted in a resource limited setting with no external funding. One of the limitations of our study was a small sample size. A prospective clinical study is required to strengthen the present study findings.

\section{CONCLUSION}

An amniotic fluid index of less than $5 \mathrm{~cm}$ observed after 37 weeks of pregnancy is a sign of poor perinatal outcome. In the presence of oligohydramnios, non-reactive NST, abnormal FHR tracings during labour, thick meconium stained, liquor, foetal distress, LSCS, low 5-minute Apgar score, low birth weight, and perinatal mortality are all common (In present study the rate of LSCS, low 5 min Apgar score and perinatal mortality number is high but statistically the difference in study and control groups are non-significant). AFI determination can be done in conjunction with other foetal surveillance techniques. It aids in the identification of infants who are at risk of having a poor perinatal outcome. AFI determination is a useful screening technique for predicting foetal distress in labour that necessitates a caesarean section. The sensitivity was $75 \%$, the specificity was $60 \%$, the positive predictive value was $48 \%$, and the negative predictive value was 88 percent.

\section{Funding: No funding sources \\ Conflict of interest: None declared}

Ethical approval: The study was approved by the Institutional Ethics Committee

\section{REFERENCES}

1. Chamberlain PF, Manning FA, Morrison I, Harman $\mathrm{CR}$, Lang CR. The relationship of marginal and decreased amniotic fluid volumes to perinatal outcome. Am J Obstet Gyencol. 1984;150:245-9.

2. Bhagat M, Chawla I. Correlation of amniotic fluid index with perinatal outcome. Ind J Obstet Gynecol. 2014;64(1):32-5.

3. Phelan JP, Smith CV, Broussard P, Small M. Amniotic fluid volume assessment with the four quadrant technique at 36-42 weeks gestation. J Reprod Med. 1987;32:540-2.

4. Locatelli A, Vergani P, Toso L, Verderio M, Pezzullo JC, Ghidini A. Perinatal outcome associated with oligohydramnios in uncomplicated term pregnancies. Arch Gynecol Obstet. 2004;269:130-3.

5. Antepartal fetal monitoring. In: Murray M, ed. Antepartal and intrapartal fetal monitoring. New York: Springer Publishing Company. 2006:455-487. 
6. Kumar PS, Kumar S, Mitra B. Perinatal outcome in pregnancy complicated with oligohydramnios at term; International Journal of Reproduction, Contraception, Obstetrics and Gynecology; 2018;7(10):3936-40.

7. Chandra P, Kaur SP, Hans DK, Kapika AK. The impact of amniotic fluid volume assessed intrapartum on perinatal outcome. Obstet Gynecol Tod. 2000;5:478-81.

8. Sriya R, Singhai S. Perinatal outcome in patients with amniotic fluid index $\leq 5 \mathrm{~cm}$. J Obstet Gynecol India. 2001;51:98-100.

9. Casey BM, Mctire DD, Bloom SL, Lucas MJ, Santos $\mathrm{R}$, Twickler DM, et al. Pregnancy outcome after antepartum diagnosis of oligohydramnios at or beyond 34 weeks gestation. Am J Obstet Gynecol.2000;1982:909-12.

10. Grubb DK, Paul RH. Amniotic fluid index and prolonged antepartum fetal heart rate declaration. Obstet Gynaecol. 1992;79(4);558-60.
11. Kumar P, Iyer S, Ramkumar V. Amniotic fluid index: a new ultrasound assessment of amniotic fluid. J Obstet Gynecol India. 1991;41:10-2.

12. Rutherford SE, Phelan JP, Smith CV, Jacobs N. The four quadrant assessment of amniotic fluid volume: an adjunct to antepartum fetal heart rate testing. Obstet Gynecol. 1987;70(3):353-6.

13. Morries JM, Thompson K, Smithey J, Gaffney G, Cooke I, Chamberlain P, et al. The usefulness of ultrasound assessment of amniotic fluid in predicting adverse outcome in prolonged pregnancy: a prospective blinded observational study. Br J Obstet Gynecol. 2003;110(11):989-94.

Cite this article as: Suneetha KB, Parvathanenidey

S. Perinatal outcome in pregnancies complicated with oligohydramnios at term. Int J Reprod Contracept Obstet Gynecol 2022;11:410-4. 